\title{
Developmental constraints and wing shape variation in natural populations of Drosophila melanogaster
}

\author{
MARIA CRISTINA PEZZOLI, DANIELA GUERRA, GIANFRANCO GIORGI, FLAVIO \\ GAROIA \& SANDRO CAVICCHI* \\ Dipartimento di Biologia evol. sper., Università di Bologna, via Selmi 3, 40126-Bologna, Italy
}

\begin{abstract}
The body sizes and shapes of poikilothermic animals generally show clinal variation with latitude. Among the environmental factors responsible for the cline, temperature seems to be the most probable candidate. In the present work we analysed natural populations of Drosophila melanogaster collected at different geographical localities to determine whether the same selective forces acting on wing development in the laboratory are also at work in the wild. We show that the temperature selection acting on wing development in the laboratory is only one of the selective forces operating in the wild. The size differences between natural populations seem to depend exclusively on cell number whereas they depend on cell area in the laboratory. The two wing compartments behave as distinct units of selection subjected to different genetic control, confirming our previous observations on laboratory populations. In addition, subunits of development defined as regions of cell proliferation centres restricted within longitudinal veins can, in turn, be considered as subunits of selection. Their interaction during development and continuous natural selection around an optimum could explain the high wing shape stability generally found in natural populations.
\end{abstract}

Keywords: developmental constraints, Drosophila melanogaster, geographical variation, wing shape.

\section{Introduction}

The body size of poikilothermic animals generally shows clinal variation with latitude. This has been well documented for many species of Drosophila in different parts of the world (David et al., 1977; Coyne \& Beecham, 1987; David \& Capy, 1988; Imasheva et al., 1994 for D. melanogaster; Capy et al., 1994 for D. melanogaster and D. simulans; Stalker \& Carson, 1947 for D. robusta; Prevosti, 1955 for $D$. subobscura; Misra \& Reeve, 1964 for D. pseudoobscura). Among the environmental factors responsible for the cline, temperature seems to be the most probable candidate. Although it does not appear to be the only factor involved in population differentiation (Sokoloff, 1966; Anderson, 1968), temperaturedirected selection for body size occurs in the laboratory (Anderson, 1966, 1973; Cavicchi et al., 1985, 1989), making it plausible that the same selective forces are at work in nature.

\footnotetext{
*Correspondence. E-mail: cavicchi_s@biblio.cib.unibo.it
}

Our work on laboratory populations of $D$. melanogaster revealed a large effect of temperature selection on body shape as well (Cavicchi et al., 1985, 1991). As shape variation reflects variations in the developmental programme of an organism, studies on shape seem relevant to understanding the relationship between development and morphological evolution. We showed that the Anterior and Posterior wing compartments, which are subunits of development (Garcia-Bellido et al., 1973), also behave as units of selection (Cavicchi et al., 1978, 1985, 1991).

Intervein regions have been recognized recently as further subunits of development, as the presumptive veins are local symmetry axes (restriction borders) of cell proliferation within the major compartments (Garcia-Bellido \& de Celis, 1992; Garcia-Bellido et al., 1994). The final size of the intervein regions ('Entelechia' condition) will depend on the maximal values as defined by the expression of vein-specific genes ('martial genes'). Mutations perturbing the system, modifying the martial values, induce an 
accommodation of the surrounding territories. We showed that after artificial selection for the size of different veins (Guerra et al., 1997) different wing shapes can be reached. In spite of that, natural selection in the laboratory drives the development to a common wing form. This means that the finegrained picture of the Drosophila wing and the way in which different intervein regions interact offer the possibility of building up the same optimum from different starting points.

Here we extend our observations to natural populations of $D$. melanogaster collected at different geographical localities to determine whether the same selective forces acting on wing development in the laboratory are also at work in the wild, and if the developmental interactions between wing territories may explain the high homeostasis generally found for wing shape in natural populations.

\section{Materials and methods}

Wild Drosophila melanogaster flies were collected from Hov, Denmark in late October 1992, from Bologna, Italy in October 1993, from Teneriffe, in the Canary Islands, and from South Mali in December 1993. According to climate, the four localities can be classified as temperate (Denmark and northern Italy) and subtropical (Teneriffe and Mali). In spring 1994, after laboratory rearing on standard medium at a temperature of $25^{\circ} \mathrm{C}, 10$ isofemale lines were established from each population. After one rearing generation, in which one pair per isofemale line was allowed to produce offspring in uncrowded conditions, the right wing of five progeny females from each line was pulled out and mounted on slides.
The areas of different wing regions, cell size and number were estimated following the procedure described in the accompanying paper (Guerra et al., 1997). Twenty flies (two for each isofemale line) of the smallest (Mali) and largest (Bologna) populations (see Results) were considered.

\section{Results}

Table 1 gives areas of the five wing regions, of the Anterior and Posterior compartments and of the total wing for each population. Both wing compartments and all the wing regions seem to follow the same variation. Southern populations showed the smallest wings but the clinal variation with latitude was only in partly evident as the flies from northern Italy had larger wings than those from Denmark.

The relative contributions of different wing regions are given in Table 2. The contribution to the total wing of the Posterior compartment increased with the whole wing size. The A, B and less so the $\mathrm{E}$ wing regions varied proportionally to the total wing area, whereas the $C$ region proportionally decreased and the $\mathrm{D}$ proportionally increased. The two wing regions at the boundary of Anterior-Posterior compartments seem therefore to be the ones responsible for the wing shape variation.

Table 3 gives intraclass correlation coefficients for isofemale lines and populations in order to estimate the amount of genetic variance for different intervein regions. $F$-tests for significance between populations (shown in Table 1) and between isofemale lines (not shown) were highly significant for all regions. In general, all areas showed similar high genetic components for both isofemale lines and populations.

Table 1 Areas of different wing regions, Anterior and Posterior compartments and the total wing in the four natural populations of Drosophila melanogaster

\begin{tabular}{lrccccc}
\hline & & & & & 3 & \multicolumn{3}{c}{$\begin{array}{c}\text { Common } \\
\text { standard } \\
\text { Wing } \\
\text { regions }\end{array}$} & Mali & Canary Is. & Italy & Denmark & error & $F$ \\
\hline A & 9.38 & 9.81 & $10.78^{\mathrm{a}}$ & $10.66^{\mathrm{a}}$ & 0.12 & $10.74^{* *}$ \\
$\mathrm{~B}$ & 13.47 & 14.34 & $15.69^{\mathrm{a}}$ & $15.35^{\mathrm{a}}$ & 0.14 & $18.89^{* *}$ \\
$\mathrm{C}$ & 16.77 & 17.54 & 19.29 & 18.39 & 0.17 & $10.95^{* *}$ \\
Anterior & 39.61 & 41.69 & 45.76 & 44.41 & 0.39 & $14.56^{* *}$ \\
D & 19.74 & 21.34 & $24.18^{\mathrm{a}}$ & $23.49^{\mathrm{a}}$ & 0.22 & $25.18^{* *}$ \\
E & 20.11 & 21.22 & 23.34 & 22.40 & 0.21 & $12.85^{* *}$ \\
Posterior & 39.85 & 42.56 & 47.52 & 45.90 & 0.42 & $19.79^{* *}$ \\
Total wing & 79.46 & 84.25 & 93.28 & 90.31 & 0.80 & $16.69^{* *}$ \\
\hline
\end{tabular}

Numbers are pixels $\times 10^{-3}$; one pixel corresponds to $2.1 \times 10^{-5} \mathrm{~mm}^{2} . F$-test from ANOVA nested design. ${ }^{a}$ Equivalent letters denote nonsignificant comparisons based on Tukey's multiple comparison test. ${ }^{* *} P<0.01$. 
Table 2 Relative contributions of the area of different wing regions and Anterior and Posterior compartments to total wing area in different populations of Drosophila melanogaster

\begin{tabular}{lcccccc}
\hline $\begin{array}{l}\text { Ratios } \\
\text { to total } \\
\text { wing area }\end{array}$ & Mali & Canary Is. & Italy & Denmark & $\begin{array}{c}\text { Common } \\
\text { standard } \\
\text { error }\end{array}$ & $F$ \\
\hline A & 0.118 & 0.118 & 0.115 & 0.118 & 0.0006 & 1.38 \\
B & 0.169 & 0.170 & 0.168 & 0.170 & 0.0007 & 0.88 \\
C & 0.211 & $0.208^{\mathrm{a}}$ & $0.207^{\mathrm{a}}$ & 0.204 & 0.0007 & $5.89^{* *}$ \\
Anterior & 0.498 & 0.495 & $0.491^{\mathrm{a}}$ & $0.492^{\mathrm{a}}$ & 0.0008 & $5.86^{* *}$ \\
D & 0.248 & 0.253 & $0.259^{\mathrm{a}}$ & $0.261^{\mathrm{a}}$ & 0.0007 & $17.30^{* *}$ \\
E & $0.253^{\mathrm{a}}$ & $0.252^{\mathrm{a}}$ & $0.250^{\mathrm{a}, \mathrm{b}}$ & $0.248^{\mathrm{b}}$ & 0.0008 & $2.36^{*}$ \\
Posterior & 0.502 & 0.505 & $0.509^{\mathrm{a}}$ & $0.508^{\mathrm{a}}$ & 0.0008 & $5.86^{* *}$ \\
\hline
\end{tabular}

$F$-test from ANOVA nested design. ${ }^{\mathrm{a}, \mathrm{b}}$ Equivalent letters denote nonsignificant comparisons based on Tukey's multiple comparison test. ${ }^{*} P<0.10,{ }^{*} * P<0.01$.

When the relative contributions of different intervein regions are considered (Table 4) all intraclass correlation coefficients of isofemale lines were significant, whereas, at the population level, only the coefficients of the C (Anterior compartment), D (Posterior compartment) and to a lesser extent $\mathrm{E}$ (Posterior compartment) regions showed significant values.

The phenotypic, genetic and partial correlations between wing regions, pooling populations, are given in Table 5. Very high phenotypic and genetic correlations are observed between all wing regions. When partial correlations are considered, much of the significance disappears, especially within the Anterior compartment. Interestingly, the D region

Table 3 Intraclass correlation coefficients \pm SE for the area of different wing regions, Anterior and Posterior compartments and the total wing of Drosophila melanogaster

\begin{tabular}{lcc}
\hline $\begin{array}{l}\text { Wing } \\
\text { regions }\end{array}$ & Isofemale lines & Populations \\
\hline A & $0.543 \pm 0.057^{* *}$ & $0.387 \pm 0.059^{* *}$ \\
B & $0.456 \pm 0.059^{* *}$ & $0.504 \pm 0.058^{* *}$ \\
C & $0.595 \pm 0.055^{* *}$ & $0.403 \pm 0.059^{* *}$ \\
Anterior & $0.559 \pm 0.057^{* *}$ & $0.468 \pm 0.059^{* *}$ \\
D & $0.611 \pm 0.054^{* *}$ & $0.560 \pm 0.057^{* *}$ \\
E & $0.560 \pm 0.057^{* *}$ & $0.436 \pm 0.059^{* *}$ \\
Posterior & $0.568 \pm 0.056^{* *}$ & $0.552 \pm 0.057^{* *}$ \\
Total wing & $0.567 \pm 0.056^{* *}$ & $0.523 \pm 0.058^{* *}$ \\
\hline
\end{tabular}

The coefficients were computed from the betweenpopulations and the pooled between- and withinisofemale lines variances (ANOVA nested design).

${ }^{* *} P<0.001$. shows a relatively high correlation with all regions that decreases with distance.

Table 6 gives cell areas and numbers of different wing regions in the smallest (Mali) and largest (Bologna) populations and their differences. The size difference between the two populations was, on average, dependent on cell number. Interestingly, it depended on cell area when the $\mathrm{C}$ and $\mathrm{E}$ regions were considered.

\section{Discussion}

In the present work we analysed size and shape variation between natural populations of Drosophila melanogaster with the aim of connecting morphological evolution to developmental organization. Here we show that the selective forces acting on wing development in the laboratory are only in part comparable to those that are at work in the wild. The morphological variation between the natural

Table 4 Intraclass correlation coefficients \pm SE for the contribution of the area of different wing regions to total wing area of Drosophila melanogaster

\begin{tabular}{lcl}
\hline $\begin{array}{l}\text { Ratios to } \\
\text { total wing area }\end{array}$ & $\begin{array}{c}\text { Isofemale } \\
\text { lines }\end{array}$ & Populations \\
\hline A & $0.399 \pm 0.059^{* *}$ & $0.017 \pm 0.024$ \\
B & $0.353 \pm 0.058^{* *}$ & $0.000 \pm 0.021$ \\
C & $0.536 \pm 0.058^{* *}$ & $0.236 \pm 0.051^{* *}$ \\
D & $0.498 \pm 0.059^{* *}$ & $0.495 \pm 0.059^{* *}$ \\
E & $0.439 \pm 0.059^{* *}$ & $0.070 \pm 0.032^{*}$ \\
\hline
\end{tabular}

The coefficients were computed for the betweenpopulations and the pooled between- and withinisofemale lines variances (ANOVA nested design). ${ }^{*} P<0.10,{ }^{* *} P<0.01$.

(c) The Genetical Society of Great Britain, Heredity, 79, 572-577. 
populations we have collected from different climates only in part follows a latitudinal cline, as the flies from northern Italy have larger wings than those from Denmark. Probably, geographical differences are not sufficient to differentiate the two populations according to the cline and the effect of local conditions and fruit trading might override the latitudinal gradient.

Our observations on the contribution of the two wing compartments to wing size and shape show that they are distinct units of selection subjected to different genetic control. The present findings overlap our previous observations on laboratory populations subjected to temperature selection (Cavicchi et al., 1985, 1991) where shape variation, as a consequence of differential selection on the two wing compartments, matches wing size variation.

In any case, the base mechanisms generating comparable phenotypes seem to be different in laboratory and natural populations. In populations subjected to temperature selection in the laboratory, variations in wing size and shape seem to be completely dependent on cell area (Cavicchi et al., 1985), whereas in nature they are dependent on cell

Table 5 Partial (pa), phenotypic (P) and genetic (G) correlation coefficients between areas of different wing regions of Drosophila melanogaster

\begin{tabular}{lccccc}
\hline $\begin{array}{l}\text { Wing } \\
\text { regions }\end{array}$ & & & & & \\
& & & $\mathrm{C}$ & $\mathrm{D}$ & $\mathrm{E}$ \\
\hline $\mathrm{A}$ & $\mathrm{pa}$ & 0.18 & 0.06 & $0.23^{*}$ & $0.23^{*}$ \\
& $\mathrm{P}$ & $0.75^{*}$ & $0.74^{* *}$ & $0.79^{* *}$ & $0.78^{* *}$ \\
& $\mathrm{G}$ & $0.85^{* *}$ & $0.80^{* *}$ & $1^{* *}$ & $0.82^{* *}$ \\
& & $(0.016)$ & $(0.018)$ & $(0)$ & $(0.018)$ \\
$\mathrm{B}$ & $\mathrm{pa}$ & & 0.18 & $0.35^{* *}$ & 0.04 \\
& $\mathrm{P}$ & & $0.80^{* *}$ & $0.84^{* *}$ & $0.76^{* *}$ \\
& $\mathrm{G}$ & & $0.87^{* *}$ & $0.88^{* *}$ & $0.87^{* *}$ \\
& & & $(0.012)$ & $(0.012)$ & $(0.014)$ \\
$\mathrm{C}$ & $\mathrm{pa}$ & & & $0.38^{* *}$ & $0.38^{* *}$ \\
& $\mathrm{P}$ & & & $0.85^{* *}$ & $0.83^{* *}$ \\
& $\mathrm{G}$ & & & $0.87^{* *}$ & $1^{* *}$ \\
& & & & $(0.010)$ & $(0)$ \\
$\mathrm{D}$ & $\mathrm{pa}$ & & & & $0.32^{* *}$ \\
& $\mathrm{P}$ & & & & $0.82^{* *}$ \\
& $\mathrm{G}$ & & & & $0.88^{* *}$ \\
& & & & & $(0.011)$ \\
\hline
\end{tabular}

Correlation coefficients were computed from the pooled variance-covariance matrix between isofemale lines (35 d.f. for P and G; 32 d.f. for pa). Standard errors of genetic correlations in parentheses (Falconer, 1981).

${ }^{*} P<0.05,{ }^{* *} P<0.01$.
Table 6 Cell area $(a)$ and cell number $(n)$ in different wing regions, Anterior and Posterior compartments and the total wing of the Mali and Bologna populations of Drosophila melanogaster and their differences

\begin{tabular}{lcccc}
\hline Wing regions & & Mali & Bologna & Difference \\
\hline A & $a$ & 0.0207 & 0.0210 & 0.0003 \\
& $n$ & 933 & 1042 & $109^{* *}$ \\
B & $a$ & 0.0171 & 0.0172 & 0.0001 \\
& $n$ & 1649 & 1861 & $212^{* *}$ \\
C & $a$ & 0.0159 & 0.0169 & $0.0010^{*}$ \\
& $n$ & 2230 & 2282 & 52 \\
Anterior & $a$ & 0.0179 & 0.0184 & 0.0009 \\
& $n$ & 4813 & 5186 & $373^{* *}$ \\
D & $a$ & 0.0168 & 0.0174 & 0.0006 \\
& $n$ & 2473 & 2786 & $313^{* *}$ \\
E & $a$ & 0.0172 & 0.0183 & $0.0011^{* *}$ \\
& $n$ & 2464 & 2601 & 137 \\
Posterior & $a$ & 0.0170 & 0.0178 & 0.0008 \\
& $n$ & 4937 & 5387 & $450^{* *}$ \\
Total wing & $a$ & 0.0174 & 0.0182 & 0.0008 \\
& $n$ & 9750 & 10573 & $823^{* *}$ \\
\hline
\end{tabular}

Comparisons are based on 20 wings per population (Student's $t$-test). Cell areas are $\mathrm{mm}^{2} \times 10^{2}$.

${ }^{*} P<0.05,{ }^{*} P<0.01$.

number (present results and Robertson, 1959). Because different targets of selection seem to exist in the laboratory and in the wild, it is reasonable to suggest, in agreement with the authors quoted in the introduction to the present work, that temperature is only one of the environmental factors involved in size variation between natural populations along a cline.

We also focused our attention on the subunits of development into which the wing is subdivided, and also recognized as units of artificial selection (Guerra et al., 1997), to verify if: (i) they may, in turn, be the target of selection in the wild; and if (ii) their interaction during development could be considered as a cause of phenotypic stability.

Three basic results seem to support the two hypotheses: (i) we found a high genetic component for the relative contribution of different wing regions to total wing surface within populations; more interestingly, (ii) they contribute differentially to the size differences between populations, generating shape differences; (iii) the contribution in terms of cell area or number to size difference between the smallest (Mali) and largest (Bologna) populations seems a peculiarity of the intervein region considered. 
The $\mathrm{D}$ region (Posterior compartment) is the most responsive to latitude, whereas the other two surrounding regions, the $\mathrm{C}$ (Anterior compartment) and, less so, the $\mathrm{E}$ (Posterior compartment) are the least responsive. The $\mathrm{D}$ region seems therefore to possess a larger genetic and/or developmental flexibility or to be the possible target of natural selection. In our opinion, both possibilities could be true. In the accompanying paper (Guerra et al., 1997) we found that the quality of the response, i.e. the correlated response of different traits and regions, was independent of the quantity of the response. In general, the correlated response to any selected trait was larger for the regions located posteriorly than for those located anteriorly to it. This is particularly evident when whole major compartments (Anterior and Posterior) are considered: both contribute similarly to the size of the wing blade when selection is performed on veins belonging to the A compartment, but the $\mathrm{P}$ compartment shows a higher response when the selection is performed on veins lying posteriorly. This means that deviation from the base allometry is reached only when the target of selection is located on the Posterior compartment that also shows the largest accommodation properties. This also means that wing shape, and therefore the way in which wing blade grows and develops, is differently affected by the positional information associated with the selected trait.

From a quantitative point of view this would be reflected in very high phenotypic correlations among wing regions; and this is what we observed both after artificial selection and in the wild $(r>0.7)$. But if accommodation occurs, it is expected that the territories surrounding the perturbed region are those that maximally accommodate. In the present experiment, the territories surrounding the $\mathrm{D}$ region were those showing the lower accommodation. Interestingly, this was reflected in a relative constancy of cell number and not of cell area. In our previous experiment (Guerra et al., 1997) we showed that, when selection was directed at posterior veins, the correlated response of the $\mathrm{D}$ region involved cell area, that of the $E$ region cell number, whereas the anterior regions behaved similarly in laboratory and natural populations. However, both selection in the laboratory and in nature changes the whole wing size through cell number. Whichever is the intimate mechanism of the integration of cell size and number at the phenotypic level, the final outcome is that the $\mathrm{C}$ and $\mathrm{E}$ regions behave as if to minimize the effects of the larger variation of the $\mathrm{D}$ region.

The partial correlation coefficients are higher between the $\mathrm{D}$ and the surrounding regions. All the anterior regions are correlated with the posterior ones, especially with the $\mathrm{D}$ region. In the last case a decreasing correlation is observed according to the distance within the wing, in agreement with our previous observation of a lower response of the regions located anteriorly to the selected trait (Guerra et al., 1997).

Genetic variability for wing regions within populations was evaluated by intraclass correlation coefficients for isofemale lines, which estimate the genetic component of variance in a broad sense, including the additive, dominance, interaction and maternal components. These estimates were found to be larger than the heritability (which accounts only for the additive component) we obtained for wing veins in our artificial selection experiment.

The contrast between the high genetic component for the deviation from the base wing allometry within populations and the low component among populations, could have both a developmental and an evolutionary explanation. In fact, accommodation, in the sense of the 'Entelechia model', can be considered a homeostatic mechanism involving the interaction of major genes responsible for the resolution of the pattern, that, per se, mechanically explains the stability of a form. In a study on the cuticular pattern in the genus Drosophila, GarciaBellido (1983) reported data on wing size differences between the smallest (D. latifasciaeformis) and largest ( $D$. gibberosa) species studied. He found a five-fold difference in the area accounted for by both the number of cells (three times) and their size (1.6 times). Interestingly, a comparison between the shapes, including many other species with different sizes, was found to be highly constant (GarciaBellido, personal communication).

The forces of natural selection, operating in a quantitative way, though not able to create new patterns, can modulate the final outcome of the developing organ. Though strongly constrained, the features of the wings in the studied populations show significant differences. This could be explained as an optimization of the wing features according to body size in different climatic areas (Capy et al., 1994; David et al., 1994). Functional studies of wing morphology in different taxa (Wootton, 1981, 1990; Ennos, 1988) explain the features of contour and venation as optimizations for flying. Moreover, the evolutionary and functional advantages of having smaller and narrower wings in a warmer climate could be in part explained by considering the thermoregulatory properties of insect wings (Kingsolver \& Koehl, 1985).

(C) The Genetical Society of Great Britain, Heredity, 79, 572-577. 


\section{Acknowledgements}

We are grateful to Drs Volker Loeschcke and Bob Krebs who provided natural populations from Denmark and the Canary Islands, and to Dr Sako Daouda who provided flies from Mali. The authors are grateful to A. Garcia-Bellido and to all the people in his laboratory for valuable discussions and suggestions. Particular thanks to Matteo Cavicchi, though he preferred to play with the MTv3 program rather than to think about his future. The work was supported by MURST.

\section{References}

ANDERSON, w. w. 1966. Genetic divergence in M. Vetukhiv's experimental populations of Drosophila pseudoobscura. 3. Divergence in body size. Genet. Res., 7, 255-266.

ANDERSON, w. w. 1968. Further evidence for coadaptation in crosses between geographic populations of Drosophila pseudoobscura. Genet. Res., 12, 317-330.

ANDERSON, w. w. 1973. Genetic divergence in body size among experimental populations of Drosophila pseudoobscura kept at different temperatures. Evolution, 27, 278-284.

CAPY, P., PLA, E. AND DAVID, J. R. 1994. Phenotypic and genetic variability of morphometrical traits in natural populations of Drosophila melanogaster and $D$. simulans. I. Geographic variations. Génét. Sél. Évol., 25, 517-536.

CAVICCHI, s., GlORGl, G. AND MOCHl, M. 1978. Investigations on early divergence between populations of Drosophila melanogaster kept at different temperatures. Genetica, 48, 81-87.

CAVICCHI, S., GUERRA, D., GIORGI, G. AND PEZZOLI, C. 1985. Temperature-related divergence in experimental populations of Drosophila melanogaster. I. Genetic and developmental basis of wing size and shape variation. Genetics, 109, 665-689.

CAVicChI, S., GUeRRA, D., NATALI, V., PEZZOLl, C. AND GIORGI, G. 1989. Temperature-related divergence in experimental populations of Drosophila melanogaster. II. Correlation between fitness and body dimensions. $J$. Evol. Biol., 2, 235-251.

CAVICCHI, S., GIORGI, G., NATALI, v. AND GUERRA, D. 1991. Temperature-related divergence in experimental populations of Drosophila melanogaster. III. Fourier and centroid analysis of wing shape and relationship between shape variation and fitness. J. Evol. Biol., 4, 141-159.

COYNE, J. A. AND BEECHAM, E. 1987. Heritability of two morphological characters within and among natural populations of Drosophila melanogaster. Genetics, 117, 727-737.

DAVID, J. C. AND CAPY, P. 1988. Genetic variation of Drosophila melanogaster natural populations. Trends Genet., 4, 89-95.
DAVID, J. C., BOQUET, C. AND DE SCHEEMAEKER-LOUIS, M. 1977. Genetic latitudinal adaptation of Drosophila melanogaster: new discriminative biometrical traits between European and Equatorial African populations. Genet. Res., 30, 247-255.

DAVID, J. R., MOReteaU, B., GaUthier, J. P., PETAVy, G., STOCKEL, A. AND IMASHEVA, A. G.. 1994. Reaction norms of size characters in relation to growth temperature in Drosophila melanogaster: an isofemale lines analysis. Génét. Sél. Évol., 26, 229-251.

ENNOS, A. R. 1988. The importance of torsion in the design of insect wings. J. Exp. Biol., 140, 137-160.

FALCONER, D. S. 1981. Introduction to Quantitative Genetics, 2nd edn. Longman, London.

GARCIA-BELLIDO, A. 1983. Comparative anatomy of cuticular patterns in the genus Drosophila. In: Goodwin, B., Holden, N. and Wylie, C. C. (eds) Development and Evolution, pp. 227-255. Cambridge University Press, Cambridge.

GARCIA-BELlido, A. AND DE CELIS, J. F. 1992. Developmental genetics of the venation pattern of Drosophila. Ann. Rev. Genet., 26, 277-304.

GARCIA-BEllido, A., RIPOll, P. AND MORATA, G. 1973. Developmental compartmentalisation of the wing disc of Drosophila. Nature New Biol., 245, 251-253.

GARCIA-BELlido, A., CORTES, F. AND MiLAN, M. 1994. Cell interactions in the control of size in Drosophila wings. Proc. Natl. Acad. Sci. U.S.A., 91, 10222-10226.

GUERRA, D., PEZzoll, M. C., GIORGI, G., GAROIA, F. AND CAVICCHI, S. 1997. Developmental constraints in the Drosophila wing. Heredity, 79, 564-571.

IMASHEVA, A. G., BUBL1, O. A. AND LAZEBNY, O. E. 1994. Variation in wing length in Eurasian natural populations of Drosophila melanogaster. Heredity, 72, 508-514.

KINGSOLVER, J. G. AND KOEHL, M. A. R. 1985. Aerodynamics, thermoregulation and the evolution of insect wings: differential scaling and evolutionary change. Evolution, 39, 488-504.

MISRA, R. K. AND REEVE, E. C. R. 1964. Clines in body dimensions in populations of Drosophila pseudoobscura. Genet. Res., 5, 240-256.

PREVOST1, A. 1955. Geographical variability in quantitative traits of Drosophila subobscura. Cold Spring Harb. Symp. Quant. Biol., 20, 294-299.

ROBERTSON, F. W. 1959. Studies in quantitative inheritance. XII. Cell size and number in relation to genetic and environmental variation of body size in Drosophila. Genetics, 44, 869-896.

SOKOLOFF, A. 1966. Morphological variation in natural and experimental populations of Drosophila pseudoobscura and Drosophila persimilis. Evolution, 20, 49-71.

STALKER, H. D. AND CARSON, H. L. 1947. Morphological variation in natural populations of Drosophila robusta. Evolution, 1, 237-248.

wootton, R. J. 1981. Support and deformability in insect wings, J. Zool., 193, 447-468.

wootTon, R. J. 1990. The mechanical design of insect wings. Sci. Am., 263, 114-120. 